Predicting the past

Marie Jahoda

The Human Legacy.

By Leon Festinger.

Columbia University Press: 1983. Pp.184.

$\$ 19.95$.

ONLY creationists any longer deny that man and monkey have evolved from the same distant ancestor. What happened so to enlarge the scope and complexity of the human mind that it produced the miracles of modern technology, art and science as well as the confusion of the social order?

After an outstanding career of forty years as a psychologist, Leon Festinger became doubtful about the significance of the questions experimental psychologists ask and has turned to archaeology in search of some clues to the answer. Having immersed himself for four years in the archaeological literature and observed some fieldwork he now presents in this book an overview of mankind's development, spanning a period from more than two and a half million years ago to the beginning of written records at about 3,000 BC. Those who know him from his previous incarnation will recognize some continuities: Festinger writes clearly, he is provocative, knowledgeable, imaginative, sometimes opinionated, sometimes wrong, but never boring (at least hardly ever).

The book is a mixture between what is known about prehistory and some speculative guesses where archaeological evidence by its very nature cannot provide answers. Throughout, it faithfully conveys the marvellous, detective-like ingenuity of archaeological reasoning from the discovery and dating of skeletons, isolated bones and tools to aspects of prehistoric ways of life. There are two parts. The first deals with biological evolution. Here the major event was the transition to bipedalism. But Festinger quotes Washburn's convincing arguments that bipedalism by itself could have been a handicap, not an adaptive development, in terms of limiting the speed of locomotion for hunting or being hunted and of greater vulnerability since any fracture would be fatal to a bipede. Only the simultaneous development of the brain and the neural system permitted the creative use of the arms freed from the task of locomotion.

This development of the mind also led to the emergence of language. From here on biological changes are minimal and the emphasis throughout the following pages is on man's creativity and capacity to innovate in efforts to control the environment. Evidence suggests that about 500,000 BP fire was under control to keep out the cold and somewhat later, covered shelters existed to protect people against wind and rain.

In the longer second part of the book Festinger deals with biologically modern

man whose artifacts can be dated to 20-30,000 yr BP. The description of the transition from the earliest human beings to modern man, the development of tools, of sedentary living which is now thought to have preceded the development of agriculture, of irrigation, of war and of slavery makes fascinating though frustrating reading. So much remains unknowable, so much speculative. Archaeological evidence from pre-literate societies compels concentration on technology but Festinger goes too far towards a more general technological determinism when he describes religion as a technology. Aware that he is stretching the term beyond its customary limits, he tries to distinguish religious from natural technologies by arguing that whereas the latter were universal skills 'religious technology' was in the hands of specialists. Yet this cannot, by his own testimony, be a crucial distinction, for he previously documents the existence of specialists in natural technologies, which has been ingeniously inferred from the uniformly high standard of tools found at single locations.

Throughout the book the dominant mood is a cheerful pessimism: man's inven-

\section{Building up power}

\section{M.C.W. Evans}

\section{Photosynthesis. Vol.1 Energy \\ Conversion by Plants and Bacteria. \\ Vol.2 Development, Carbon Meta- \\ bolism, and Plant Productivity. \\ Edited by Govindjee. \\ Academic: 1983. Vol.1 Pp.796. \$79, £52; \\ Vol. 2 Pp.580. \$59, £39.}

PHOTOSYNTHESIS, the most important of biological processes, is the subject of a huge research effort involving a wide range of disciplines. Collating and presenting this research in a readily accessible form is, to say the least, a difficult undertaking.

Over the years Govindjee has written and edited a number of books with this objective. These two volumes represent his most ambitious attempt to date. They cover the full range of photosynthesis from the picosecond time scale of the primary photochemistry, through the slowing series of electron transport, ATP synthesis and carbon fixation, to the physiological and ecological problems of productivity and global photosynthetic yields. There is even room for the editor's personal interest in the effects of carbon on the primary reactions and for the heresy that bicarbonate is the source of oxygen in photosynthesis.

To achieve this wide-ranging coverage, Govindjee has assembled a distinguished cast of contributors, and to obtain balance between studies on plants and on bacteria, he has induced some improbable author combinations. The result is that virtually every chapter is of a high standard. Only the tiveness has indeed found technological solutions for one major problem after the other only to discover that every problem solved gave rise as an unanticipated consequence to new ones. In the last chapter where Festinger reflects on the present the cheerfulness disappears and there remains a bleak pessimism. The only hope is that ". . . in five or ten or twenty thousand years a new species of human beings, more able than we, will be around." This resignation stems from some rather simple diagnoses of our immediate social problems such as "inefficiency, featherbedding, strikes, seniority systems".

One could list more serious problems, indeed he does, and even imagine possible solutions not necessarily of a technological kind. But to long for a dim future in which all problems are solved without creating new ones is to long for Nirvana. The essence of being alive is to face challenges and to act. Without this last chapter the book would be a stimulating introduction to some aspects of our prehistoric past.

Marie Jahoda is Professor Emeritus of Socia Psychology and Consultant to the Science Policy Research Unit, University of Sussex.

molecular biologists have failed to produce a synthesis, apparently falling out after writing a joint introduction.

Each of the books has an introductory chapter, intended to allow readers from other fields to understand the basis of the subject, the important advances and the salient problems remaining. These are followed by the specialist chapters grouped into subject areas. The first volume covers the membrane-dependent processes, the initial photochemistry, electron transport and ATP synthesis; the second, the "dark reactions" of carbon dioxide fixation, plant growth and productivity.

The first volume suffers rather badly from the common deficiency of multiauthor books, with considerable overlap between the chapters, and even duplication of figures and tables in some places. In Vol.2 this has been avoided on the whole, though a major omission is an account of bacterial and algal ecology and productivity.

Although the two-volume work can be criticized on a number of points, there is little doubt that it will be the basic reference book on photosynthesis for a number of years. It has the advantage of dealing with both bacteria and plants and of providing chapters on all aspects of photosynthesis. Although specialists will find that details are already out of date, it provides a good record of the main advances of the past ten years. As such it should stimulate the exchange of ideas between the different disciplines involved, and will be an excellent source for both advanced teaching and research.

M.C.W. Evans is Professor of Plant Chemistry at University College London. 